\title{
Correction
}

\section{Correction: Microbial Community Profiling of Human Saliva Using Shotgun Metagenomic Sequencing}

\section{The PLOS ONE Staff}

Figure 4 is an accidental duplication of Figure 3. Please see the correct Figure 4 here.

Citation: The PLOS ONE Staff (2014) Correction: Microbial Community Profiling of Human Saliva Using Shotgun Metagenomic Sequencing. PLoS ONE 9(8): e106124. doi:10.1371/journal.pone.0106124

Published August 18, 2014

Copyright: (๑) 2014 The PLOS ONE Staff. This is an open-access article distributed under the terms of the Creative Commons Attribution License, which permits unrestricted use, distribution, and reproduction in any medium, provided the original author and source are credited. 
VFD12_006 GAIIx Species Abundance ( $>2 \%)$
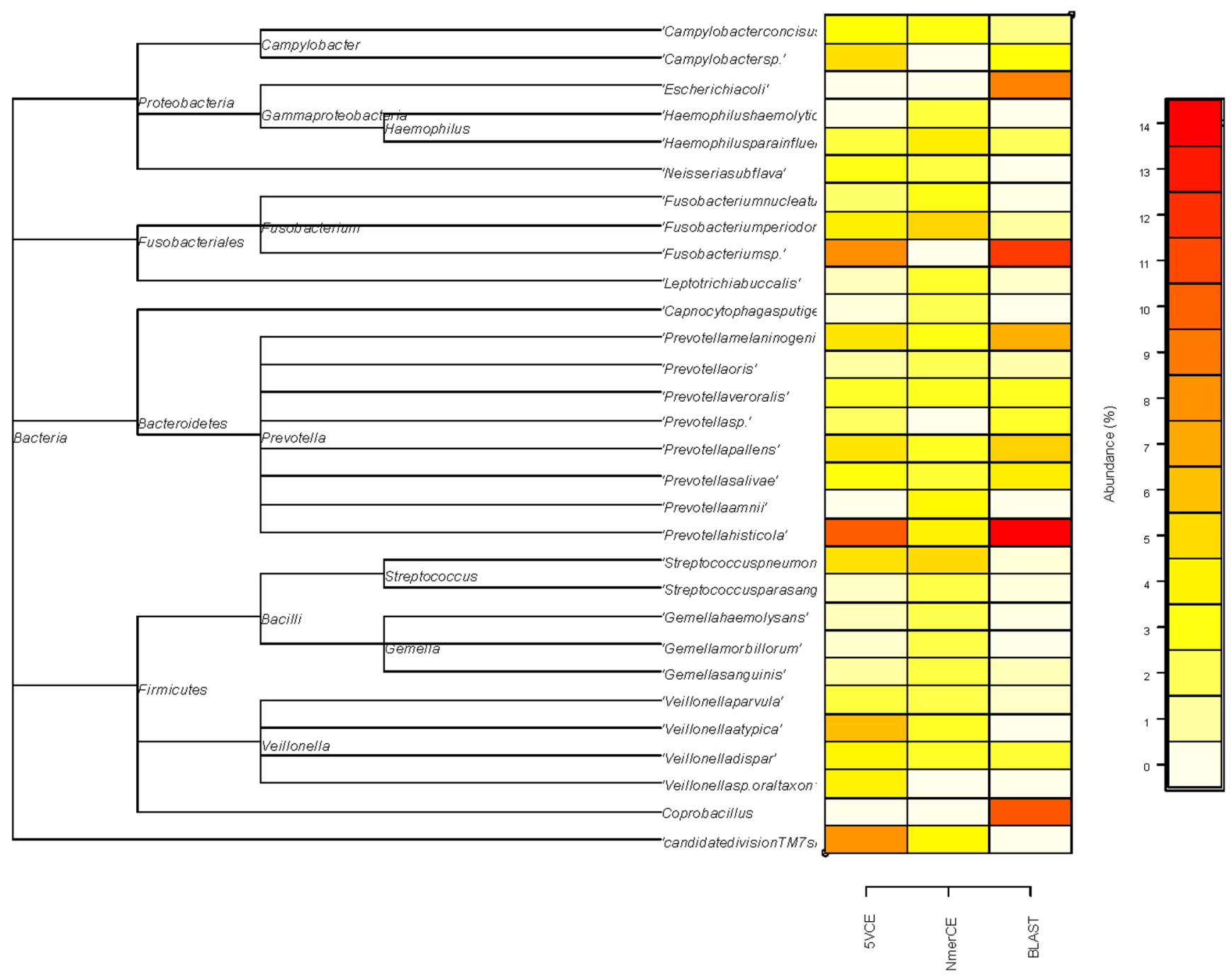

Figure 4. Relative abundance of species in VFD12-006 estimated by GAllx sequencing and BLAST (microbial reference database), 5VCE, and NmerCE algorithms.

doi:10.1371/journal.pone.0097699.g004

\section{Reference}

1. Hasan NA, Young BA, Minard-Smith AT, Saeed K, Li H, et al. (2014)

Microbial Community Profiling of Human Saliva Using Shotgun Metagenomic

Sequencing. PLoS ONE 9(5): e97699. doi:10.1371/journal.pone.0097699 